\title{
Spanish validation of the Problem Gambling Severity Index: A confirmatory factor analysis with sports bettors
}

\author{
HIBAI LOPEZ-GONZALEZ ${ }^{1 *}$, ANA ESTÉVEZ ${ }^{1}$ and MARK D. GRIFFITHS ${ }^{2}$ \\ ${ }^{1}$ Psychology Department, University of Deusto, Bilbao, Spain \\ ${ }^{2}$ International Gaming Research Unit, Psychology Department, Nottingham Trent University, Nottingham, UK
}

(Received: April 13, 2018; revised manuscript received: July 30, 2018; accepted: August 6, 2018)

\begin{abstract}
Background and aims: The Problem Gambling Severity Index (PGSI) is one of the most widely used screening tools for problem gambling (PG). However, to date, no empirically validated adaptation of the instrument to Spanishspeaking countries exists. Methods: A sample of 659 sports bettors $\left(M_{\mathrm{age}}=35.1\right.$ years, $S D=10.12,74.2 \%$ males $)$ were recruited through an online research panel. A confirmatory factor analysis (CFA) was performed to confirm its construct validity. The participants were administered the Spanish version of the PGSI, along with the adaptation to Spanish of the DSM-IV PG instrument for convergent validity. Results: The CFA of the Spanish PGSI showed satisfactory construct validity. The internal consistency $\left(\alpha_{\text {ordinal }}=.97\right)$ as well as its convergent validity with the DSM-IV scores $(r=.77, p<.001)$ was good. Conclusion: The Spanish adaptation of the PGSI offers satisfactory validity and reliability properties, and is a good psychometric instrument for exploring the social consequences of PG in Spanish-speaking contexts.
\end{abstract}

Keywords: gambling, problem gambling, PGSI, sports betting, gambling disorder, validation

\section{INTRODUCTION}

Problem gambling (PG) is the only non-substance-related addiction officially recognized in the latest (fifth) edition of the Diagnostic and Statistical Manual of Mental Disorders (American Psychiatric Association [APA], 2013). Those in the general population who have gambling disorder (past 12 months) have been estimated to be $0.2 \%-0.3 \%$, whereas lifetime prevalence rates range from $0.4 \%$ to $1 \%$ (APA, 2013). Recent systematic reviews have noted that prevalence estimates vary between territories, timeframes, and assessment instruments used (Calado \& Griffiths, 2016; Williams, Volberg, \& Stevens, 2012).

In several English-speaking countries, the Problem Gambling Severity Index (PGSI; Ferris \& Wynne, 2001) has progressively replaced previous instruments assessing PG prevalence, and is arguably the most widely used PGscreening tool currently (Calado \& Griffiths, 2016). The PGSI was conceived to reflect more socially oriented (rather than clinical) PG aspects (Petry, 2016). Therefore, it complements development of DSM gambling disorder criteria without being outdated. The PGSI has adapted well to Internet-based gambling activities, as well as newer gambling forms like fantasy gaming (Nower, Caler, Pickering, \& Blaszczynski, 2018) and online sports betting (Lopez-Gonzalez, Estévez, \& Griffiths, 2018).

Some scholars have criticized the PGSI classification structure (Petry, 2016), whereas others argue that it underestimates the PG prevalence among women (Orford, Wardle, Griffiths, Sproston, \& Erens, 2010). The same authors also note that the PGSI assesses gambling problems as a continuum instead of dichotomous (yes/no) alternatives (e.g., DSM criteria). Subsequent assessments and reassessments of PGSI validity and reliability have confirmed its efficacy (Currie, Casey, \& Hodgins, 2010; Miller, Currie, Hodgins, \& Casey, 2013). Some studies have used the PGSI without previously validating the instrument in their own language, or administered it in English form to non-native English speakers (Bonnaire et al., 2017; Hanss et al., 2015).

This study was conducted in Spain, and the PG prevalence is in line with most of the western countries. Using the Spanish National Opinion Research Center DSM Screen for Gambling Problems (NODS; National Opinion Research Center, 1999), the latest prevalence study showed a PG incidence of $0.3 \%$ (past year) and $0.9 \%$ (lifetime) (Dirección General de Ordenación del Juego, 2016). Pilatti and Tuzinkievich (2015) reported the use of a Spanish PGSI version in the development of their Gambling Motives Questionnaire (Argentinian sample), but was not psychometrically validated. Given that Spanish is spoken by an estimated 470 million people worldwide (i.e., in the top three most spoken languages globally), and that 21 countries' official language is Spanish (World Atlas, 2018), a Spanish PGSI is warranted. Consequently, a Spanish PGSI is likely to promote research on PG in

\footnotetext{
* Corresponding author: Hibai Lopez-Gonzalez; Psychology Department, University of Deusto, Av de las Universidades, 24, Bilbao 48007, Spain; Phone: +34 685711 501; Fax: +34 944139 085; E-mail: hibai.lopez@deusto.es
}

This is an open-access article distributed under the terms of the Creative Commons Attribution-NonCommercial 4.0 International License, which permits unrestricted use, distribution, and reproduction in any medium for non-commercial purposes, provided the original author and source are credited, a link to the CC License is provided, and changes - if any - are indicated. 
Spanish-speaking countries and facilitates cross-cultural studies using related screening instruments.

\section{METHODS}

\section{Participants and procedure}

The target population was Spanish adult gamblers and a Barcelona market research company collected the data. They offered their online research panel (containing approximately 1,200 adults) who had claimed in past studies to have bet on sports. In March 2017, 848 participants from the research panel accessed a Qualtrics online survey, and accepted the study's terms and conditions. To participate, the survey asked a filter question: "Have you placed at least one bet on sports in the past 12 months?" Only those who answered "yes" continued $(n=709)$. Some participants did not complete the questionnaire leaving 659 fully completed questionnaires for analysis. All participants received points that could be redeemed for gifts in the market research company's online store. Participants' mean age was 35.1 years $(S D=10.12)$ ranging from 18 to 66 years with significantly more males $(74.2 \% ; n=489)$.

\section{Measures}

Sociodemographic variables. These variables included age, gender, living situation (i.e., who they lived with), occupation, and education.

Problem Gambling Severity Index (PGSI; Ferris \& Wynne, 2001). The English PGSI comprises nine items to assess gambling severity, with five items assessing adverse consequences of gambling, and four items assessing problematic behaviors of gamblers (Holtgraves, 2009). The PGSI can also be used to assess gambling problems among online participants (Gainsbury et al., 2016). Each item is rated by respondents on a 4-point scale (i.e., $0=$ never, $1=$ sometimes, $2=$ most of the time, and $3=$ almost always). Final scores range from 0 to 27 and allow for the categorization of respondents into four exclusive groups: $0=$ non-problem gamblers, $1-2=$ low-risk gamblers, $3-7=$ moderate-risk gamblers, and $>8=$ problem gamblers. The original scale validation showed a very good reliability of .84 (Ferris \& Wynne, 2001).

Standardized procedures were followed (Brislin, 1970) to adapt the PGSI to Spanish language. The original English version was independently translated into Spanish by two of the present authors who are fluent in both languages. These two versions were compared and every discrepancy was discussed until reaching an agreement. The consensual Spanish version was sent to an external examiner (English native speaker and linguist), with previous experience in psychometric validations. This person back-translated into English and compared both versions looking for incongruences. These were dealt with by introducing changes to the scale until a final Spanish version was agreed with the back-translator. This final version was further assessed by a Spanish expert in gambling who had first-authored the Spanish DSM-IV gambling disorder criteria. The translation from English into Spanish presented no real obstacles in terms of cultural or linguistic differences, and was performed in compliance with the International Test Commission Guidelines for Translating and Adapting Tests (International Test Commission, 2010).

Stinchfield's measure of DSM-IV diagnostic criteria for PG (Stinchfield, 2003). This instrument is a 19-item self-administered questionnaire reflecting the 10 diagnostic PG criteria of the Diagnostic and Statistical Manual of Mental Disorders - Text Revised (APA, 2000) in a dichotomous format (i.e., yes/no). Each criterion has two items (except Criterion 4). Endorsing at least one of the two items is sufficient to endorse the whole criterion. Respondents can score from 0 to 10 , with scores of $5+$ indicating PG (Stinchfield, 2003). This study used the validated Spanish version (Jiménez-Murcia et al., 2009). This showed high internal consistency (Cronbach's $\alpha=.95$ ), with low false positives and moderate false negatives, and high sensitivity and specificity when applying the cut-off point of 5. This instrument assessed the convergent validity of the Spanish PGSI. Scores on DSM-based instruments such as the NODS have been found to correlate highly with PGSI scores $(r=.83)$ (Currie et al., 2010).

\section{Analytical approach}

To explore the fit of the Spanish PGSI and confirm its unidimensional structure, a confirmatory factor analysis (CFA) was carried out using structural equation modeling Mplus 6.12 software. The remaining descriptive and inferential statistical analyses were conducted using IBM SPSS 21. Finally, the ordinal alpha coefficient was calculated to assess the reliability of the instrument using a macro for IBM Microsoft Excel designed by Domínguez-Lara (2012). The characteristics of the PGSI scoring system, which consists in less than five categories per item (i.e., four responses per item), make the data more unlikely to follow a normal distribution, informing the decision to treat responses as ordinal. Therefore, use of conventional CFA approaches such as the maximum likelihood technique was not advisable. A weighted least squares mean and variance adjusted estimation were favored, because they provide good estimations for non-normal distributions, and are especially robust in data sets larger than 200 cases $(\mathrm{Li}, 2016)$.

In order to validate model fit, the following indices were calculated: root mean square of approximation (RMSA), comparative fit index (CFI), Tucker-Lewis fit index (TLI), and weighted root mean square residual (WRMR). The thresholds for a good fit were considered following conventional values as recommended in the literature $\mathrm{Hu}$ \& Bentler, 1999; Jackson, Gillaspy, \& Purc-Stephenson, 2009): RMSA $<0.08$, CFI $>0.95$, TLI $>0.95$, and WRMR $<0.90$. In addition, a $\chi^{2}$ test was run expecting a statistically non-significant result (i.e., $p$ value greater than .05 ).

\section{Ethics}

The study obtained approval from the university research ethics committee of University of Deusto, and is conducted in accordance with the principles of the Declaration of 
Helsinki. All respondents had to click an "accept" hyperlink to participate in the survey, and were informed about the (a) topic of the study, (b) right to stop participating at any time, and (c) anonymity and confidentiality of data provided. In addition, they were reassured of their right to withdraw data from the study at any point prior to publication, and were given the contact details of the principal investigator. The market research company who collected the sample only invited adults to participate (18+ years).

\section{RESULTS}

\section{Descriptive statistics}

In terms of living situation, 292 participants (44.3\%) lived only with their partner, 259 with family members other than partner $(39.3 \%), 76$ on their own $(11.5 \%), 24$ with friends $(3.6 \%)$, and 8 in other kinds of living arrangement $(1.2 \%)$. Most participants $(n=401)$ had university education $(60.8 \%), 139$ professional or vocational training (21.1\%), 114 secondary education (17.3\%), and 5 lower than secondary education $(0.8 \%)$. As to occupation, most were working $(n=517,78.5 \%)$, whereas others were studying $(n=84,12.7 \%)$, unemployed $(n=42,6.4 \%)$, retired $(n=6,0.9 \%)$, or in an unspecified occupational situation $(n=10,1.5 \%)$.

\section{Construct validity}

The one-factor model of the Spanish PGSI was tested by means of a CFA. In the analyzed sample $(N=659)$, the tests showed the following results: $\chi^{2}(27)=96.57, p<.05, \mathrm{CFI}=$ 0.997, TLI $=0.996$, RMSEA $=0.063$ [90\% CI: $0.049-0.076$ ], $\mathrm{WRMR}=0.772$. The $p$ value for the $\chi^{2}$ test (i.e., $p<.05$ ) was expected to be non-significant. Nevertheless, $\chi^{2}$ results are sensitive to large sample sizes $(n>200)$, sometimes producing false positives, in which case it is recommended to weigh the indicators of the rest of the fit exams before discarding the proposed model (Hair, Anderson, Tatham, \& Black, 2010). All fit indicators unambiguously demonstrated a very good overall fit between the model and the data. Therefore, the model was deemed appropriate.

\section{Item analysis and reliability}

All items of the Spanish PGSI showed a great factor loading regarding the only dimension they assessed (i.e., PG), ranging from $r_{\mathrm{s}}=.77$ to .96 . Similarly, item-total correlation, calculated using Spearman's $\rho$ due to the ordinal nature of the data, also showed high coefficients $(0.70-0.80)$. These results combined with those provided by the polychoric correlations (items correlating between .64 and .91), provided evidence of the adequacy of including all nine items of the Spanish PGSI. The overall scale reliability was excellent (.97).

Regarding internal consistency, and given the characteristics of the 4-point response scale in the original PGSI, data were analyzed as an ordinal variable. Consequently, internal consistency was estimated using an ordinal alpha coefficient, following expert guidelines (Elosua \& Zumbo, 2008; Zumbo, Gadermann, \& Zeisser, 2007). This resulted in an $\alpha_{\text {ordinal }}$ of .97 . This estimate was well above the conventional threshold of good reliability. Both item analysis and reliability tests demonstrated the relevancy of the included items, with none of the items showing inconsistent psychometric properties.

\section{Convergent validity}

Participants' responses to the Spanish PGSI were then compared to the responses of the most recently validated Spanish PG-screening instrument (i.e., Spanish DSM-IV). This comparison was used to determine the convergent validity of the new instrument. PGSI and DSM-IV scores were highly and positively correlated (Spearman's $\rho=.745, p<.001)$. Convergence was further assessed by analyzing the discrepancies and agreements between the participants that each instrument identified as problem or non-problem gamblers. After applying the recommended cut-off points in the score system for PG detection (i.e., 5 for DSM-IV and 8 for PGSI), a contingency table showed that both scales had a considerable degree of mutual agreement (Cohen's $\kappa$ coefficient $>.61$ ). In addition, and despite the PGSI not being a diagnostic tool, the scale showed great accuracy and power in predicting PG in the DSM-IV scale $($ sensitivity $=0.93$ and specificity $=0.79)$.

\section{Within sample incidence of $P G$}

Participants' PGSI scores were categorized into four groups according to gambling severity. The results showed the following distribution: (a) the non-PG group (i.e., scores of 0 ) comprised 256 participants (38.8\% of the sample), (b) the low-risk gambling group (i.e., scores 1-2) comprised 175 participants $(26.6 \%)$, (c) the moderate-risk gambling group (i.e., scores 3-7) comprised 102 participants (15.5\%), and (d) the PG group (score $\geq 8$ ) comprised 126 participants $(19.1 \%)$.

The items most frequently endorsed by problem gamblers (i.e., responding anything other than "never") were: first, feeling guilty about the way they gambled; second, having been criticized about their gambling; and third, trying to win back the money they lost (i.e., "chasing losses") (Table 1). However, among moderate-risk gamblers, the most frequently endorsed item was chasing losses, followed by feeling guilty, and being criticized about their gambling. Two thirds of the participants $(64.5 \%)$, categorized by the PGSI as low-risk gamblers, reported chasing their losses, whereas $17.7 \%$ felt guilty about their gambling, and $13.1 \%$ felt criticized for gambling.

No significant associations were found between PG severity and gender, age, level of education, or occupation. A small but significant difference was found concerning cohabitation. After applying Bonferroni correction to adjust the $p$ values to control for familywise errors, a significant association emerged between cohabitation and PG severity $\left[\chi^{2}(12)=27.210, p<.007\right]$. Residuals with a $z$ score higher than 2 showed that problem gamblers were much more likely to live only with their partner $(Z=3.6)$, whereas those 
Table 1. Percentage (\%) of item endorsement per problem gambling severity group

\begin{tabular}{lcccrc}
\hline Item brief description & $\begin{array}{c}\text { Non-problem } \\
\text { gambler }\end{array}$ & $\begin{array}{c}\text { Low-risk } \\
\text { gambler }\end{array}$ & $\begin{array}{c}\text { Moderate-risk } \\
\text { gambler }\end{array}$ & $\begin{array}{c}\text { Problem } \\
\text { gambler }\end{array}$ & \begin{tabular}{c}
$\chi^{2}(d f)$ \\
\hline 1. Betting more than can afford to lose
\end{tabular} \\
2. Betting more for same excitement & 0 & 12.0 & 46.0 & 88.8 & $420.93(9)^{*}$ \\
3. Chasing losses & 0 & 6.8 & 46.0 & 92.8 & $492.06(9)^{*}$ \\
4. Borrowing money & 0 & 64.5 & 78.4 & 95.2 & $521.45(9)^{*}$ \\
5. Self-perception of gambling problems & 0 & 1.7 & 14.7 & 91.2 & $512.25(9)^{*}$ \\
6. Health problems & 0 & 5.7 & 41.1 & 86.5 & $524.74(9)^{*}$ \\
7. Criticized over gambling behavior & 0 & 4.5 & 32.3 & 92.0 & $517.32(9)^{*}$ \\
8. Financial problems & 0 & 13.1 & 47.0 & 95.2 & $499.54(9)^{*}$ \\
9. Feeling guilty about gambling & 0 & 1.1 & 14.7 & 91.2 & $519.17(9)^{*}$ \\
\hline
\end{tabular}

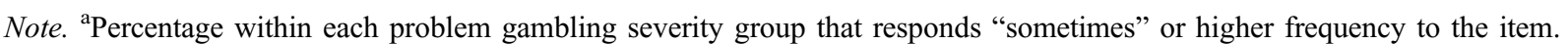
$* p<.001$.

living with their families were less likely to be problem gamblers $(Z=-3.4)$.

\section{DISCUSSION}

The purpose of this study was to adapt the PGSI (Ferris \& Wynne, 2001) for Spanish-speaking countries. A convenience sample of 659 Spanish sports bettors was recruited to explore the internal consistency and validity of the new instrument. In general, the Spanish PGSI showed great convergent validity with the Spanish DSM-IV. Furthermore, the CFA that is carried out confirmed the PGSI's unidimensional solution. As it has typically been the case in other countries (Barbaranelli, Vecchione, Fida, \& Podio-Guidugli, 2013), the convergent validation of the PGSI performed well and was predictive of the scores in other DSM-based tools. Its reliability was similarly high $\left(\alpha_{\text {ordinal }}=.97\right)$, even higher than in previous PGSI adaptations including China $(\alpha=.77$; Loo, Oei, \& Raylu, 2011), New Zealand ( $\alpha=.86$; Devlin \& Walton, 2012), and Sweden ( $\alpha=.82$; Svensson \& Romild, 2014 ), although the ordinal nature of the reliability measure utilized here does not exactly equate the measures reported in these aforementioned studies.

This study demonstrated the convenience of the existing cut-off point of 8 to discriminate between those already suffering $P G$ and other at-risk gamblers, with accurate diagnosis of problematic participants both by the Spanish PGSI and the DSM-IV. This threshold has caused controversy in the past, especially in studies where moderate-risk and problem gamblers were merged to allow for greater statistical power (Currie, Hodgins, \& Casey, 2013). In these cases, both false positives and false negatives were more common. In this study, the size of the surveyed sample allowed for statistical significance without the need for category mergers. Other authors have argued that the PGSI is relatively weak in evaluating the low- to moderate-risk spectrum of gambling problems (Jackson, Wynne, Dowling, Tomnay, \& Thomas, 2010; Miller et al., 2013), although such debates are usually consubstantial to cut-off score decisions, and vary between countries. For instance, in territories with higher PG prevalence rates (e.g., South Africa), lower cut-off points have been proposed for efficient PG detection (Dellis et al., 2014).
The results obtained here showed that both at-risk gamblers and problem gamblers identified chasing losses, feeling guilty, and being criticized, as the top three items of the scale they related most to. Low- and moderate-risk gamblers had chasing losses as the most endorsed item on the scale. This has also been reported in a Finnish PGSI study, where chasing losses was the most endorsed item (Raisamo, Mäkelä, Salonen, \& Lintonen, 2015). In this study, chasing losses was endorsed by almost $65 \%$ of low-risk gamblers, which considers the 2-point maximum score necessary to be categorized in that group, meaning that many individuals are considered to be low-risk gamblers because of this particular behavior. However, as the disorder develops, feeling guilty about one's gambling behavior and being criticized for gambling, take priority and become more prevalent.

There are some limitations associated with this study. First, the validation was carried out with general population data, rather than a clinical group previously diagnosed with gambling disorder. Second, the self-report nature of the data collected makes this study vulnerable to several respondents' biases including social desirability and memory recall (Pontes \& Griffiths, 2016). Third, the sample used for the Spanish PGSI was not intended to be representative of the Spanish population, or any particular age group within it. Therefore, the recruitment method utilized might have introduced a number of biases in the sample. The use of an online research panel could have overestimated the proportion of Internet bettors while underestimating those bettors who primarily bet offline. Fourth, the study's results cannot be considered as indicative of the prevalence rate of PG in Spain, since among other things, the filter question (i.e., having placed a bet in the past 12 months) only selected those individuals who actively engaged in sports betting, ignoring all other types of gamblers and non-gamblers. Fifth, the self-selection method of the online panel could have prompted that participants with a greater interest in sports betting might have been more likely to opt in. Similarly, those already experiencing gambling-related harm might have found an incentive in participating in the survey. Finally, all the participants engaged in sports betting and some may argue that this is a limitation, given that the PGSI was developed to be used in epidemiological studies of the general population. However, given that all the participants were gamblers and the PGSI assesses the 
potential for at-risk and PG, such a population is arguably advantageous in this respect. In addition, the items are generic and are not developed to differentiate between different types of problem gamblers; therefore, the participants all being sports bettors are unlikely to have made any material difference. In addition, previous research using nationally representative samples has shown that individuals with higher PGSI scores are likely to engage in many different types of gambling (Wardle et al., 2011).

\section{CONCLUSIONS}

Notwithstanding these limitations, the Spanish PGSI adaptation was found to offer good validity and reliability properties. The PGSI stands as a complementary screener to the DSM-based diagnostic tools, which are primarily focused on the clinical aspects of gambling disorder, whereas a new Spanish PGSI is a good psychometric tool for assessing PG from the perspective of its social consequences. A copy of the Spanish PGSI is made available at the end of this article (Appendix).

Funding sources: This work was supported by the Government of the Basque Country, Spain, under grant reference (Eusko Jaurlaritza, POS_2015_1_0062). This work has also been funded by the Spanish Organization of the Blind (ONCE, III International Award).

Authors' contribution: HL-G developed the concept and design of the study, dealt with the recruitment of the sample, and wrote the first draft of the manuscript. AE contributed to the statistical analysis of the data. MDG contributed to the final draft of the manuscript. All authors critically reviewed the final version of the draft and approved its submission.

Conflict of interest: HL-G and AE declare no competing interests. MDG declared that he had received funding for a number of research projects in the area of gambling education for young people, social responsibility in gambling, and gambling treatment from the Responsibility in Gambling Trust, a charitable body that funds its research program based on donations from the gambling industry. He also undertakes consultancy for various gaming companies in the area of social responsibility in gambling.

\section{REFERENCES}

American Psychiatric Association [APA]. (2000). Diagnostic and statistical manual of mental disorders (4th ed., text rev.). Washington, DC: American Psychiatric Association.

American Psychiatric Association [APA]. (2013). Diagnostic and statistical manual of mental disorders (5th ed.). Arlington, VA: American Psychiatric Association.

Barbaranelli, C., Vecchione, M., Fida, R., \& Podio-Guidugli, S. (2013). Estimating the prevalence of adult problem gambling in Italy with SOGS and PGSI. Journal of Gambling Issues, 1(28), 1-24. doi:10.4309/jgi.2013.28.3

Bonnaire, C., Kovess-Masfety, V., Guignard, R., Richard, J. B., du Roscoät, E., \& Beck, F. (2017). Gambling type, substance abuse, health and psychosocial correlates of male and female problem gamblers in a nationally representative French sample. Journal of Gambling Studies, 33(2), 343-369. doi:10.1007/ s10899-016-9628-4

Brislin, E. W. (1970). Back-translation for cross-cultural research. Journal of Cross-Cultural Psychology, 1(3), 185-216. doi:10. $1177 / 135910457000100301$

Calado, F., \& Griffiths, M. D. (2016). Problem gambling worldwide: An update and systematic review of empirical research (2000-2015). Journal of Behavioral Addictions, 5(4), 592-613. doi:10.1556/2006.5.2016.073

Currie, S. R., Casey, D., \& Hodgins, D. C. (2010). Improving the psychometric properties of the Problem Gambling Severity Index. Ottawa, ON: Canadian Consortium for Gambling Research.

Currie, S. R., Hodgins, D. C., \& Casey, D. M. (2013). Validity of the Problem Gambling Severity Index interpretive categories. Journal of Gambling Studies, 29(2), 311-327. doi:10.1007/ s10899-012-9300-6

Dellis, A., Sharp, C., Hofmeyr, A., Schwardmann, P. M., Spurrett, D., Rousseau, J., \& Ross, D. (2014). Criterion-related and construct validity of the Problem Gambling Severity Index in a sample of South African gamblers. South African Journal of Psychology, 44(2), 243-257. doi:10.1177/0081246314522367

Devlin, M. E., \& Walton, D. (2012). The prevalence of problem gambling in New Zealand as measured by the PGSI: Adjusting prevalence estimates using meta-analysis. International Gambling Studies, 12(2), 177-197. doi:10.1080/14459795.2011. 653384

Dirección General de Ordenación del Juego. (2016). Estudio sobre prevalencia, comportamiento y características de los usuarios de juegos de azar en España 2015 [Study on prevalence, behaviour, and characteristics of gamblers in Spain 2015]. Madrid, Spain: Ministerio de Hacienda y Administraciones Públicas.

Domínguez-Lara, S. (2012). Propuesta para el cálculo del alfa ordinal y theta de armor [Proposal for the calculation of the Alpha Ordinal and Theta de Armor]. Revista de Investigación en Psicología, 15(1), 213-217. doi:10.15381/rinvp.v15i1.3684

Elosua, P., \& Zumbo, B. D. (2008). Coeficientes de fiabilidad para escalas de respuesta categórica ordenada [Reliability coefficients for scales with ordinal categorical data]. Psicothema, 20(4), 896-901.

Ferris, J., \& Wynne, H. (2001). The Canadian Problem Gambling Index: Final report. Canadian Centre on Substance Abuse. Ottowa, Canada: Canadian Consortium for Gambling Research.

Gainsbury, S., King, D. L., Russell, A. M. T., Delfabbro, P., Derevensky, J., \& Hing, N. (2016). Exposure to and engagement with gambling marketing in social media: Reported impacts on moderate-risk and problem gamblers. Psychology of Addictive Behaviors, 30(2), 270-276. doi:10.1037/adb0000156

Hair, J. F., Anderson, R. E., Tatham, R. L., \& Black, W. C. (2010). Multivariate data analysis (7th ed.). Uppersaddle River, NJ: Pearson Education International.

Hanss, D., Mentzoni, R. A., Blaszczynski, A., Molde, H., Torsheim, T., \& Pallesen, S. (2015). Prevalence and correlates 
of problem gambling in a representative sample of Norwegian 17-year-olds. Journal of Gambling Studies, 31(3), 659-678. doi:10.1007/s10899-014-9455-4

Holtgraves, T. (2009). Evaluating the Problem Gambling Severity Index. Journal of Gambling Studies, 25(1), 105-120. doi:10. 1007/s10899-008-9107-7

Hu, L., \& Bentler, P. M. (1999). Cutoff criteria for fit indexes in covariance structure analysis: Conventional criteria versus new alternatives. Structural Equation Modeling: A Multidisciplinary Journal, 6(1), 1-55. doi:10.1080/10705519909540118

International Test Commission. (2010). International test commission guidelines for translating and adapting tests. Retrieved April 12, 2018, from http://doi.org/10.1027/19012276.61.2.29

Jackson, A. C., Wynne, H., Dowling, N. A., Tomnay, J. E., \& Thomas, S. A. (2010). Using the CPGI to determine problem gambling prevalence in Australia: Measurement issues. International Journal of Mental Health and Addiction, 8(4), 570-582. doi:10.1007/s11469-009-9238-9

Jackson, D. L., Gillaspy, J. A., \& Purc-Stephenson, R. (2009). Reporting practices in confirmatory factor analysis: An overview and some recommendations. Psychological Methods, 14(1), 6-23. doi:10.1037/a0014694

Jiménez-Murcia, S., Stinchfield, R., Álvarez-Moya, E., Jaurrieta, N., Bueno, B., Granero, R., Aymamí, M. N., Gómez-Peña, M., Martínez-Giménez, R., Fernández-Aranda, F., \& Vallejo, J. (2009). Reliability, validity, and classification accuracy of a Spanish translation of a measure of DSM-IV diagnostic criteria for pathological gambling. Journal of Gambling Studies, 25(1), 93-104. doi:10.1007/s10899-008-9104-x

Li, C.-H. (2016). Confirmatory factor analysis with ordinal data: Comparing robust maximum likelihood and diagonally weighted least squares. Behavior Research Methods, 48(3), 936-949. doi:10.3758/s13428-015-0619-7

Loo, J. M. Y., Oei, T. P. S., \& Raylu, N. (2011). Psychometric evaluation of the Problem Gambling Severity Index-Chinese version (PGSI-C). Journal of Gambling Studies, 27(3), 453-466. doi:10.1007/s10899-010-9221-1

Lopez-Gonzalez, H., Estévez, A., \& Griffiths, M. D. (2018). Internet-based structural characteristics of sports betting and problem gambling severity: Is there a relationship? International Journal of Mental Health and Addiction. Advance online publication. doi:10.1007/s11469-018-9876-x

Miller, N. V., Currie, S. R., Hodgins, D. C., \& Casey, D. (2013). Validation of the Problem Gambling Severity Index using confirmatory factor analysis and rasch modelling. International Journal of Methods in Psychiatric Research, 22(3), 245-255. doi:10.1002/mpr.1392

National Opinion Research Center. (1999). Gambling impact and behavior study: Report to the National Gambling Impact Study Commission. Chicago, IL: National Opinion Research Center, University of Chicago.
Nower, L., Caler, K. R., Pickering, D., \& Blaszczynski, A. (2018). Daily fantasy sports players: Gambling, addiction, and mental health problems. Journal of Gambling Studies, 34(3), 727-737. doi:10.1007/s10899-018-9744-4

Orford, J., Wardle, H., Griffiths, M., Sproston, K., \& Erens, B. (2010). PGSI and DSM-IV in the 2007 British Gambling Prevalence Survey: Reliability, item response, factor structure and inter-scale agreement. International Gambling Studies, 10(1), 31-44. doi:10.1080/14459790903567132

Petry, N. M. (2016). Gambling disorder: The first officially recognized behavioral addiction. In N. M. Petry (Ed.), Behavioral addictions: DSM-5® and beyond (pp. 7-42). New York, NY: Oxford University Press.

Pilatti, A., \& Tuzinkievich, F. B. (2015). Evaluation of the psychometric properties of the Gambling Motives Questionnaire in Argentinian young people and adults. Adicciones, 27(1), 17-26. doi:10.20882/adicciones. 190

Pontes, H. M., \& Griffiths, M. D. (2016). Portuguese validation of the Internet Gaming Disorder Scale-Short-Form. Cyberpsychology, Behavior, and Social Networking, 19(4), 288-293. doi:10.1089/cyber.2015.0605

Raisamo, S. U., Mäkelä, P., Salonen, A. H., \& Lintonen, T. P. (2015). The extent and distribution of gambling harm in Finland as assessed by the Problem Gambling Severity Index. European Journal of Public Health, 25(4), 716-722. doi:10.1093/eurpub/cku210

Stinchfield, R. (2003). Reliability, validity, and classification accuracy of a measure of DSM-IV diagnostic criteria for pathological gambling. American Journal of Psychiatry, 160(1), 180-182. doi:10.1176/appi.ajp.160.1.180

Svensson, J., \& Romild, U. (2014). Problem gambling features and gendered gambling domains amongst regular gamblers in a Swedish population-based study. Sex Roles, 70(5-6), 240-254. doi:10.1007/s11199-014-0354-Z

Wardle, H., Moody, A., Spence, S., Orford, J., Volberg, R., Jotangia, D., Griffiths, M. D., Hussey, D., \& Dobbie, F. (2011). British Gambling Prevalence Survey 2010. London, UK: The Stationery Office.

Williams, R. R. J., Volberg, R. A., \& Stevens, R. M. G. (2012). The population prevalence of problem gambling: Methodological influences, standardized rates, jurisdictional differences, and worldwide trends. Guelph, ON: Ontario Problem Gambling Research Centre and the Ontario Ministry of Health and Long Term Care.

World Atlas. (2018). How many Spanish speaking countries are there in the world? Retrieved April 12, 2018, from https://www.worldatlas.com/articles/how-many-spanishspeaking-countries-are-there-in-the-world.html

Zumbo, B. D., Gadermann, A. M., \& Zeisser, C. (2007). Ordinal versions of coefficients alpha and theta for Likert rating scales. Journal of Modern Applied Statistical Methods, 6(1), 21-29. doi:10.22237/jmasm/1177992180 


\section{APPENDIX}

Validación al español del Problem Gambling Severity Index

(Ferris \& Wynne, 2001). Validación hecha por Lopez-Gonzalez, H., Estévez, A., y Griffiths, M. D.

Piensa en los últimos 12 meses...

\begin{tabular}{ll}
\hline Ítems & \multicolumn{1}{c}{ Pregunta } \\
\hline 1 & ¿Has apostado más de lo que realmente podías permitirte perder? \\
2 & Teniendo en cuanta los últimos 12 meses, ¿has necesitado jugar cantidades de dinero cada vez mayores para conseguir la misma \\
& sensación de excitación? \\
3 & Cuando juegas dinero, ¿vuelves otro día para intentar recuperar el dinero perdido? \\
5 & ¿Has pedido dinero o vendido algo para conseguir dinero para jugar? \\
6 & ¿Crees que tienes o has tenido alguna vez problemas con el juego? \\
7 & ¿El juego te ha ocasionado algún problema de salud, incluido estrés o ansiedad? \\
8 & ¿que era cierto o no? \\
9 & ¿El juego te ha ocasionado algún problema económico en ti o en tu casa? \\
\hline
\end{tabular}

\section{Instrucciones}

Respuestas: Nunca $=0$; Algunas veces $=1$; La mayoría de las veces $=2$; Casi Siempre $=3$.

Puntuación: La puntuación total puede variar de 0 a 27 y se interpreta de acuerdo a las siguientes categorías.

$0=$ jugador no problemático sin consecuencias negativas. $1-2=$ Riesgo bajo. Jugador que experimenta pocos problemas y con pocas o ninguna consecuencia negativa. 3-7 = Riesgo moderado. Jugador que experimenta problemas moderados con algunas consecuencias negativas. 8 o más = Jugador problemático. 